\title{
ESTUDO PREVIO SOBRE INTEGRAÇÃO DE ENFERMAGEM EM CENTRO CIRÚRGICO E ENFERMAGEM CIRÚRGICA
}

\author{
Sonia Della Torre Salzano : \\ Denise Ribeiro Cardoso *:*
}

\section{I - INTRODUÇÃO}

O ensino de Enfermagem cirúrgica dissociado de Enfermagem em Centro cirúrgico tem sido objeto de discussão nas Escolas de Enfermagem, constituindo um problema que vem nos preocupando cada vez mais. Isto dificulta a aprendizagem pela falta de seqüência na assistência ao paciente no pré, trans e pós operatório, além da duplicação no ensino de algumas unidades e sub-unidades de ambos os programas, o que significa má utilização das horas docentes e discentes.

Analisando os programas de Enfermagem Cirúrgica e Enfermagem em Centro Cirúrgico, deparamo-nos com vários assuntos que cieveriam ser planejados em boco comum, tais como: assistência ao paciente no pré, trans e pós operatórios, planos cirúrgicos, hemostasia, princípios de esterilização, posições cirúrgicas, cuidados com a unidade de eletro-cirurgia, etc. Neste caso esses assuntos poderiam

* Professor Assistente Doutor do Departamento de Enfermagem MédicoCirúrgica - Docente da disciplina de Enfermagem em Centro Cirúrgico da EEUSP.

** Professor Assistente Doutor do Departamento de Enfermagem MédicoCirúrgica - Docente da disciplina de Enfermagem Cirúrgica da EEUSP. 
ser ministrados de forma mais detalhada, esgotando os aspectos de interesse para ambas as disciplinas, numa seqüência lógica. $O$ ato cirurgico é um período do tratamento cirúrgico e não deve ser considerado a parte como vem acontecendo.

Frente a essa problemática sentimos necessidade de estudar a possibilidade de uma integração dessas disciplinas, podendo ser elas planejadas de várias formas pelos respectivos docentes. CASTRO (1972) sugere várias formas de integração; a) as disciplinas podem ser mantidas autônomas; neste caso os docentes planejam seus programas de atividades conjuntamente, de maneira a tornar evidentes as inter-relações existentes entre os conhecimentos e os seus objetivos comuns; b) garantida a individualidade da disciplina, uma delas pode ser tomada como disciplina básica. Neste caso seria apresentado previamente seu planejamento e a outra procuraria com ela coordenar-se; c) uma outra modalidade seria a fusão das disciplinas, não simplesmente reunidas, mas reestruturadas com novos objetivos e seqüência original.

Evitar-se-ia dessa forma, a duplicação no ensino de temas pertencentes a ambas as disciplinas o que conduz à experiências mais significativas que tenham funcionalidade para o aprendizado. Estariamos neste caso condicionando a integração preconizada por KOPKINS (1943). Esse autor analisa integração em termos de interação do indivíduo com o meio. Seria para o autor "um processo que ocorre dentro do aluno"; tem-se que proporcionar a ele ocasião vara que integre suas diversas experiências didáticas, isto é, oferecer oportunidade para analisar situações clínicas reais e aplicar princípios aprendidos teoricamente, na solução de problemas.

Julgamos que a integração das disciplinas seja uma forma de favorecer a interação aluno-meio, ou seja, interação com a vida real.

Antes de enfocar os aspectos comuns das disciplinas, apresentaremos os objetivos de ambas para maior clareza na exposição. 
II - OBJETIVOS GERAIS ATUAIS DAS DISCIPLINAS

Enfermagem em Centro

Enfermagem Cirúrgica

Cirúrgico

1. Planejar e prestar assistência física e psicológica aos pacientes na sala de operações antes, durante e após a cirurgia e fazer as anotações necessárias.

2. Planejar e perparar a sala de operações e circular em cirurgias gastrointestinal, do pescoço e ginecológica, observando os aspectos éticos envolvidos.

3. Reconhecer as fontes de contaminação da ferida operatória e empregar os meios existentes para evitá-las.

4. Descrever os métodos de hemostasia e os princípios físicos empregados no funcionamento da unidade de eletro-cirurgia e relacionálos aos cuidados ao paciente durante a cirurgia.

5. Descrever e aplicar os princípios físico-químicos e microbiológicos nos processos de esterilização do material cirúrgico.
1. Discorrer sobre os cuidados de enfermagem no pré e pós operatório de paciente com afecções cirúrgicas digestivas, pulmonares, cardiovasculares, do sistema nervoso e da tireoide.

2. Prestar assistência de enfermagem a pacientes no pré e pós operatórios acompanhando a evolução clínica e relacionando-a com exames e tratamento.

2.

3. Citar causas, sinais, sintomas e tratamento cirúrgico das afecções citadas.

4. Reconhecer sinais e sintomas de complicações pós operatórias.

4.

2.

4.

5. Discorrer sobre os cuidados de enfermagem a pacientes com fratura. 
Em ambas as discipinas, verifica-se que teoricamente não estão estabelecidos os limites entre a assistëncia no pré e pós operatório imediato e mediato, mas isso ocorre no trabalho de campo quando os grupos de alguns alunos são distribuídos, em épocas diferentes, com outras docentes para os estágios de Enfermagem Cirúrgica e Enfermagem em Centro Cirúrgico. Isto prejudica não só a seqüência natural da aprendizagem como também 0 aproveitamento proporcionados pelas disciplinas.

$\mathrm{Na}$ observação quanto aos aspectos éticos proposto no segundo objetivo de Enfermagem em Centro Cirúrgico, teríamos melhores condições de avaliar o estudante se o mesmo desse continuidade a essa assistência de enfermagem no pós operatório, o que envolveria um relacionamento direto aluno-paciente-família.

Por outro lado, para que o aluno possa prestar os cuidados de enfermagem no pré e pós operatórios de pacientes com afecções cirúrgicas, necessita de conhecimento e vivência do trans operatório, sem o que é prejudicada a observação e detecção de sinais e sintomas de complicações pós anestésicas e do trauma cirúrgico. Este período, trans operatório, é descrito através de informações rápidas e superficiais da docente de Enfermagem Cirúrgica, o que leva o aluno a imaginar uma situação não vivida, quando o mesmo ainda não passou pelo estágio de Enfermagem em Centro Cirúrgico.

Quanto às fontes de infecção da ferida operatória constitui um conhecimento importante e fundamental para ambas as disciplinas, bem como o problema das infecções cruzadas. Exemplificando: na Enfermagem em Centro Cirúrgico aborda-se possíveis fontes de infecção, tais como: paciente, planta, ambiente, pessoal e material, não só visando a incisão cirúrgica como também o aparelho respiratório e os meios profiláticos. Ora, este assunto é básico na assistência ao paciente tanto no pré como no pós operatório. Em Enfermaegm Cirúrgica dá-se grande ênfase aos meios profiláticos tanto no pré-operatório (higiene corporal, destacando condições bucais, preparo do campo operatório, exercícios pulmonares e todas as orientações para obter cooperação do paciente no pós operatório quanto à movimentação, tosse, preparo gastro-intestinal, etc.), como nos cuidados pós operatórios (curativo da ferida operatória, cuidados $\mathrm{ccm}$ os drenos, continuidade da higiêne corporal, dos exercícios respiratórios, da mobilização e deambulação precoce).

A aplicação dos princípios preventivos da infecção cruzada constitui fundamentação básica para ambas as disciplinas. 
Pela situação dos estágios em separado essa continuidade de conhecimentos é dificultada, exigindo do professor uma abordagem rápida e superficial de conhecimentos ainda não ministrados pela outra disciplina.

Os métodos de hemostasia incluindo a eletro-cirurgia são ministrados em Enfermagem em Centro Cirúrgico com certa profundidade. Na eletro-cirurgia é abordada a importância do manuseio do aparelho, assim como os cuidados em relação ao paciente para evitar os problemas de queimadura. Esses conhecimentos também são importantes para a assistência de enfermagem no pós operatório, pois eles devem fundamentar a observação da integridade corporal e sinais de hemorragia que constitui um dos primeiros cuidados ao receber o paciente operado na enfermaria.

Em Enfermagem em Centro Cirúrgico os alunos têm oportunidade de conhecer e aplicar os princípios físico-químicos e microbiológicos nos processos de esterilização do material cirúrgico. Em Enfermagem Cirúrgica com freqüência o estudante manipula quer material simples (para dissecação de veia, colocação de intra-cath), quer instrumental mais complicado (para uma revisão de emergência de sutura operatória); como também utiliza-se constantemente de material para curativos, sondagens, recolocação de rrenos e punções, podendo estes apresentarem-se contaminados. Para manipulação cesse instrumental exige-se aplicação de princípios químicos e microbiológicos, que quando ainda não adquiridos pelos alunos em Enfermagem em Centro Cirúrgico, traz dificudade para o estudante assim como para o docente neste estágio.

Para que os estudantes atinjam os objetivos propostos por ambas as disciplinas, uma das estratégias empregadas é o Seminário, €m que os alunos apresentam o estudo de um paciente cirúrgico. desde sua internação até a alta. Quando eles estão estagiando em Centro Cirúrgico, se detêm mais sobre a assistência no trans operatório relacionada com a assistência pré e pós operatória. Quando em Enfermagem Cirúrgica, o estudante é orientalo a dar ênfase na assistência pré e pós operatória sem deixar também de abordar o trans operatório.

Essa situação traz para o aluno certa dificuldade, quando não lhe é possibilitada uma assistência contínua (pré, trans e pós operatóric) a esse paciente. Como conseqüência parte desse estudo torna-se teórico e irreal, por não ter sido uma situação totalmente vlvida pelo estudante. 
Em Enfermaegm em Centro Cirúrgico, outra estratégia adotada, é a de visitas a centros cirúrgicos da capital com roteiro pré formulado, visando reforço no conhecimento sobre: assistência prestada ao paciente na sala de operações assim como o preparo do ambiente cirúrgico, meios físicos e químicos de esterilização, planta de centro cirúrgico e de centro de material . Essas visitas são realizadas por pequenos grupos de alunos, que distribuídos em vários hospitais devem, a posteriori, apresentar relatórios com a finalidade de troca de experiências entre eles.

Essas visitas têm sido um bom método de aprendizagem, pois através dos relatórios tem-se observado que os alunos ampliam sua visão quanto à problemática de Centro Cirúrgico. Parém, quando eles vão focalizar o paciente cirúrgico se limitam a assistência prestada na sala de operações, tendo poucas condições de fazer referência à assistência no pré e pós operatório, dada a não integração das duas disciplinas.

Em Enfermagem Cirúrgica os alunos apresentam no final do estágio um trabalho escrito sobre determinado paciente ao qual eles tenham prestado assistência no pré e pós operatório. $O$ objetivo desse trabalho é conduzir o aluno a uma avaliação não só dos cuidados por ele prestado ao paciente como também das condições pré operatórias influindo na recuperação pós operatória. Ora, neste trabalho eles tentam abordar o trans operatório, baseando-se em informações da equipe e consulta bibliográfica, incorrendo na mesma situação irreal criticada na estratégia do Seminário.

Em Enfermagem em Centro Cirúrgico os alunos têm um estágio de observação nas salas de operações de ORL., OFT., NEURO. e ORTOPEDIA, cuja observação é orientada por um roteiro previamente formulado pelos docentes, devendo apresentar, a posteriori, um relatório detalhado. Isto tem sido válido, pois dá ao aluno uma visão da assistência de enfermagem a esse tipo de paciente. Devido ao curto espaço de tempo do estágio, há impossibilidade de dar maior experiência aos alunos nestas especialidades.

Por outro lado, em Enfermagem Cirúrgica, pela mesma problemática de tempo, os alunos não tem oportunidade de nem sequer observar um paciente nas especialidades tais como ORL, OFT., etc. Isto tem sido causa de preocupação, pois na vida profissional, eles podem enfrentar sem nenhum conhecimento e experiência prévia, situações bem simples como seja a de um amigdalectomizado, um operado de catarata, etc. 
Após o comentário dos pontos comuns às disciplinas focalizadas parece que se torna maior a necessidade de entrosamento entre elas, pois só assim conseguir-se-á um ensino mais globalizado, com economia de tempo docente e discente e maior satisfação para ambas as partes.

\section{III - REFERENCIAS BIBLIOGRAFICAS}

1. CASTRO, A.D. - Diđäitica para escola de $1 .^{\circ}$ e $20^{\circ}$ graus, $2 .^{\mathrm{a}}$ ed. Editora Edibell Ltda. São Paulo, 1972.

2. AGUAYO, A.M. - Didática da escola nova, 13.a ed. Companhia Editora São Paulo, 1966.

3. KORPKINS, L. T. et al. - Integration. Its meaning and application. D. Appleton Car Company. New York, 1943.

4. RIVERA, S.F. - Formas de integração do ensino. Rev. Bras. de Enfermagem XIII (1) : 68, março, 1960. 